\title{
ANÁLISE MICROBIOLÓGICA DE MÃOS DE MANIPULADORES DE ALIMENTOS DO MUNICÍPIO DE SANTO ANDRÉ
}

\section{MICROBILOGICAL ANALYSIS OF FOOD HANDLERS' HANDS IN SANTO ANDRÉ}

\author{
Edeli Simioni de Abreu ${ }^{1}$ \\ Flavia da Silva Medeiros ${ }^{2}$ \\ Deborah Adolfo Santos ${ }^{2}$
}

RESUMO: Os coliformes termotolerantes são definidos como "capazes de fermentar a lactose em meio EC, com produção de gás, no meio de 48 horas, a 45,5 'C". O presente estudo teve por objetivo verificar a presença ou ausência de coliformes termotolerantes em amostras das mãos de manipuladores de alimentos de vias públicas do município de Santo André. A população de estudo foi composta por 12 manipuladores de cachorro-quente. Os métodos utilizados foram: um questionário observacional e um aplicado ao manipulador, além de coleta de amostras das mãos dos manipuladores, submetidas a meios de cultura. Todas as amostras inoculadas no meio de cultura nutriente apresentaram contaminação. Dos 108 tubos de Durhan, com caldo VBB inoculados 100 (92,59\%), apresentaram turvação do meio e 50 (46,30\%) apresentaram formação de gás no interior do tubo de Durhan caracterizando a presença de coliformes totais. Foram inoculados 36 caldos EC, os quais $91,66 \%$ e $50 \%$ das amostras coletadas das unhas, $83,33 \%$ e 58,33\% dos dedos e $75 \%$ e $66,67 \%$ das palmas das mãos apresentaram turvação e formação de gás, respectivamente, evidenciando a presença de coliformes termotolerantes. Vinte e quatro amostras foram utilizadas para confirmação da presença de E. coli, quinze (62,5\%), apresentaram colônias verde-brilhantes em meio EMB. Concluiu-se que o principal motivo pelo qual várias amostras se apresentaram contaminadas por coliformes, foi a higiene das mãos insuficiente, já que 100\% dos manipuladores não lavavam as mãos durante o trabalho, mostrando a necessidade de atitudes dos órgãos competentes para eliminar ou minimizar os riscos de contaminação.

Palavras-chave: microbiologia de alimentos; higiene de alimentos; comida de rua.

ABSTRACT: The thermo-resistant coliforms are defined as "able to ferment lactose in EC medium, with gas production in 48 hours, at $45.5{ }^{\circ} \mathrm{C}$." The present study was intended to verify the presence or absence of thermoresistant coliforms in samples from the hands of street food handlers in Santo André. The studied population was composed for 12 hotdog venders. The handlers were observed and given a questionnaire. In addition, samples were collecting from their hands and cultured. All samples were contaminated. Of the 108 inoculated Durhan tubes with VBB medium, 100 (92.59\%) showed turbidity and 50 (46.30\%) showed gas formation inside the Durhan tube indicating the presence of coliform. Of the 36 tubes inoculated, $91.66 \%$ and $50 \%$ of nail, $83.33 \%$ and $58.33 \%$ of the finger, and $75 \%$ and $66.67 \%$ of the palm samples showed turbidity and gas formation, respectively, which indicates the presence of coliform organisms. Twenty-four samples were used to confirm the presence of $E$. coli, and fifteen (62.5\%) showed bright green colonies. The main reason why several samples were contaminated by coliform was probably insufficient hand hygiene, because $100 \%$ of food handlers do not wash their hands during work. This shows the need for actions by competent government institutions to eliminate or minimize contamination risks.

Keywords: food microbiology; food hygiene; street food.

\footnotetext{
${ }^{1}$ UPM - Universidade Presbiteriana Mackenzie, CCBS, São Paulo, SP. Alameda São Caetano, 857 - apto. 43 - São Caetano do Sul - SP, Brasil - CEP: 09560051

E-mail: edelisabreu@gmail.com

${ }^{2}$ FEFISA - Faculdades Integradas de Santo André, Santo André, SP.
} 


\section{INTRODUÇÃO}

Nos últimos dez anos, houve aumento crescente no número de manipuladores que comercializam alimentos, principalmente 0 cachorro-quente. Esse aumento se deve à maior procura por esse tipo de alimento devido à praticidade e agilidade em seu preparo (LUCCA; TORRES, 2002). Com expansão desses serviços, os alimentos ficaram mais expostos e sujeitos à contaminação microbiana devido às práticas incorretas de manipulação e processamento.

Segundo Souza e Campos (2003), para o alimento se tornar fonte de saúde imprescindível ao ser humano, deve ser processado dentro de um controle de etapas, na qual a temperatura em que alimento é mantido, tempo gasto durante seu preparo, utilização de matéria-prima de boa qualidade, condições higiênico-sanitárias satisfatórias, e sendo convenientemente armazenado e transportado para obter-se uma melhoria na qualidade e uma minimização dos riscos de um surto de origem alimentar. A qualidade é uma característica multidimensional do alimento, sendo uma combinação de atributos microbiológicos, nutricionais e sensoriais e este controle em todas as etapas do processamento de alimentos tem como objetivo assegurar a qualidade, promovendo a saúde do consumidor.

A qualidade higiênico-sanitária tem sido amplamente estudada e discutida, uma vez que doenças vinculadas por alimentos é a principal causa de morbidade nos países americanos (AKUTSU et al., 2005). A qualidade sanitária desses alimentos é fundamental considerando a amplitude do público atendido. Os surtos geralmente têm origem em falhas desse tipo de serviço, incluindo: refrigeração inadequada, preparação de alimentos com amplo espaço de tempo (maior que 12 horas), processamento térmico insuficiente, conservação a quente imprópria, alimentos contaminados, contaminação cruzada, manipuladores infectados, uso de produtos clandestinos e higienização incorreta de utensílios e mãos de manipuladores de alimentos (CARDOSO; SOUZA; SANTOS, 2005).

Considerando que as mãos dos manipuladores de alimentos podem constituir fonte potencial de patógenos em serviços de alimentação, este trabalho tem por objetivo verificar a presença e realizar contagem de coliformes totais em amostras das mãos de manipuladores de alimento $e$ identificar as condições higiênico-sanitárias do trabalho.

\section{DESENVOLVIMENTO: MATERIAIS E MÉTODOS}

A amostra foi composta por 12 manipuladores de alimentos de ambos os sexos, comerciantes de cachorro-quente de vias públicas do município de Santo André. O estudo foi realizado utilizando-se um questionário contendo 14 questões a respeito dos manipuladores de alimentos e do seu ambiente de trabalho, além de um check-list desenvolvido de acordo com as Normas de Boas Práticas de Fabricação (Anexos I e II).

Para coleta de amostras foram utilizados zaragatoa (swab), tubos de ensaio e tampa, luvas descartáveis estéreis, caixa de isopor, etiqueta adesiva e caneta. 
Os tubos de ensaio continham $10 \mathrm{~mL}$ de diluente (água tamponada estéril) cada, os quais foram armazenados no isopor $e$ transportados até o local da coleta.

$\mathrm{Na}$ coleta das amostras, em triplicata, passou-se o swab umedecido com água peptonada sobre a superfície da mão dos manipuladores de alimentos e posteriormente este foi depositado no tubo de ensaio com água peptonada, lacrado e etiquetado. Os tubos foram acondicionados no isopor e transportados ao laboratório interdisciplinar da FEFISA. Os swab contendo as amostras colhidas foram estriados em placas de Petri contendo cerca de $20 \mathrm{~mL}$ de ágar nutriente solidificado. No laboratório as placas foram invertidas e incubadas a $35^{\circ} \pm 2{ }^{\circ} \mathrm{C}$ por 24 horas para crescimento dos microrganismos.

Coliformes totais: foram isoladas de cada uma das quatro placas uma colônia suspeita, cultivadas no ágar nutriente, e, foram inoculadas separadamente em tubos de ensaio contendo caldo lactosado de-bili-verde-brilhante (VBB) a $2 \%$ com tubos de Durhan invertido, incubados a $35{ }^{\circ} \mathrm{C} \pm 2$ ${ }^{\circ} \mathrm{C}$ por 24 a 48 horas. Considerou-se a amostra como positiva quando ocorreu a turvação do meio e a presença de gás do interior do tubo de Durhan.

Coliformes termotolerantes: Caldos positivos de VBB foram semeados em tubos contendo caldo EC com tubos de Durhan invertido, sendo estes incubados a $45^{\circ} \mathrm{C}$ por 24 a 48 horas. Considerou-se positivo o tubo que apresentasse turvação do meio, bem como a presença de gás do interior do tubo de Durhan.

Escherichia coli: Cada caldo de EC positivo foi semeado em EMB com o auxilio de uma alça de platina. As placas foram invertidas e incubadas a $35^{\circ} \mathrm{C} \pm 2{ }^{\circ} \mathrm{C}$ por 24 horas.

Foram consideradas positivas para $E$. coli, as placas que apresentaram colônias verde-brilhantes. Se as placas apresentaram colônias negras, secas e chatas ou claras, convexas, brilhantes e com centro negro estas foram consideradas coliformes.

Um termo de consentimento elaborado de acordo com a legislação e Comitê de Ética foi apresentado e assinado pelos manipuladores de alimentos (Processo CEO $\left.n^{\circ} 1378\right)$.

\section{RESULTADOS E DISCUSSÃO}

No total 12 manipuladores aceitaram participar da pesquisa, dos quais $50 \%$ tinham idade entre 15 e 25 anos, 25\% entre 26 e 55 anos e $25 \%$ com idade superior a 55 anos. Quanto ao sexo, 91,67\% eram do sexo feminino e $8,33 \%$ do sexo oposto. O grau de escolaridade entre os manipuladores era de $25 \%$ com ensino fundamental, $66,66 \%$ com ensino médio, sendo $8,33 \%$ com ensino médio incompleto e $8,33 \%$ analfabeto.

Sessenta e seis por cento dos manipuladores de alimentos exercia essa profissão há mais de 10 meses. Em geral, $91,67 \%$ tinham jornada de trabalho entre 4 e 6 dias semanais, nos quais eram produzidos, diariamente, de acordo com $75 \%$ dos manipuladores, mais de 50 lanches/dia, podendo chegar a 250 lanches/dia. A grande quantidade de lanches produzidos diariamente evidencia a necessidade de medidas corretivas para eliminar ou diminuir os riscos de surtos alimentares, já que o 
número de pessoas que consomem esse tipo de lanche é muito alto.

Durante a observação, verificou-se que $66,67 \%$ dos componentes dos lanches eram mantidos em embalagens convencionais e armazenados em isopores com outros alimentos, os quais não eram devidamente fechados.

Com relação à análise microbiológica os seguintes dados foram obtidos. Para cultivo das colônias que deram seguimento ao trabalho, foi utilizado meio de cultura nutriente, no qual todas as amostras inoculadas apresentaram crescimento microbiano.

$\mathrm{Na}$ Fig. 1 pode ser observado tubo apresentando turvação, caracterizado pela ausência da coloração esverdeada do caldo.

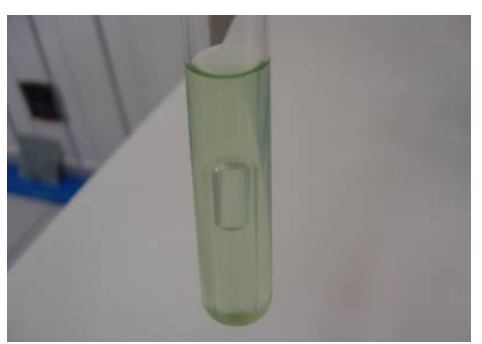

Fig. 1 - Tubo de Durhan invertido com turvação, caracterizados pela ausência da coloração esverdeada do caldo.

A Tabela 1 mostra os resultados encontrados da inoculação em meio VBB, com as colônias cultivadas em caldo nutriente. De todas as partes das mãos analisadas (palma, dedos e unhas) 3 amostras foram analisadas, estando os resultados na tabela a seguir.

Tabela 1 - Distribuição das amostras inoculadas em caldo VBB segundo turvação, formação de gás e flutuação do tubo de Durhan

\begin{tabular}{lccccccccc}
\hline Manipulador & T & palma & FG & F & T & Dedos & \multicolumn{3}{c}{ Unhas } \\
\hline 1 & 3 & 2 & 2 & 3 & 2 & 0 & 3 & 1 & 1 \\
2 & 3 & 1 & 1 & 3 & 2 & 1 & 3 & 3 & 3 \\
3 & 3 & 3 & 1 & 3 & 3 & 3 & 3 & 2 & 1 \\
4 & 3 & 3 & 3 & 3 & 3 & 1 & 3 & 2 & 2 \\
5 & 3 & 1 & 1 & 3 & 3 & 2 & 2 & 2 & 2 \\
6 & 3 & 1 & 1 & 3 & 3 & 3 & 3 & 1 & 1 \\
7 & 2 & 2 & 2 & 3 & 0 & 0 & 3 & 2 & 0 \\
8 & 3 & 1 & 1 & 3 & 1 & 1 & 1 & 1 & 1 \\
9 & 3 & 2 & 0 & 3 & 2 & 2 & 3 & 2 & 2 \\
10 & 2 & 1 & 1 & 0 & 3 & 3 & 3 & 0 & 0 \\
11 & 3 & 0 & 0 & 3 & 2 & 2 & 3 & 1 & 1 \\
12 & 3 & 0 & 0 & 3 & 1 & 1 & 3 & 2 & 2 \\
\hline Legenda: T = turvação do meio; FG $=$ formação de gás; F = flutuação do tubo de Durhan
\end{tabular}

De 108 amostras, 100 (92,59\%) apresentaram turvação do meio, das quais, $86,11 \%$ apresentaram turvação do meio em 3 das 3 amostras inoculadas, e em apenas 8 amostras $(7,41 \%)$ não ocorreu turvação ou fermentação da lactose. Essa é uma das características necessárias para verificação da presença de coliformes totais nas mãos dos manipuladores analisados além da produção de gás pelos microrganismos devido à metabolização dos carboidratos a fim de obter energia para o seu crescimento (FRANCO; LANDGRAF, 2003, p. 83). 
Em 50 (46,30\%) das amostras analisadas, houve formação de gás, com posterior flutuação do tubo de Durhan presente no tubo de ensaio com caldo VBB. Das 3 amostras coletadas da palma das mãos do manipulador, 4, dos dedos dos manipuladores, 3, 5 e 6, e das unhas do manipulador 2 apresentaram em 100\% das amostras flutuação do tubo de Durhan e turvação do meio. A flutuação do tubo de Durhan é a prova de que houve formação de gás no interior do tubo de ensaio. Características apresentadas pelas bactérias determinadas coliformes termotolerantes, mas como esse caldo identifica a presença de coliformes totais, fez-se necessária a etapa seguinte para confirmação da presença de coliformes termotolerantes nas amostras coletadas das mãos dos manipuladores de alimentos de Santo André (TRABULSI; ALTERTHUM, 2005).

A presença de coliformes totais na maioria das amostras indica condições higiênico-ambientais insatisfatórias dos alimentos preparados. O mesmo foi observado no estudo de Falcão et al., (1983), onde a maioria das amostras também apresentou condições higiênicas e sanitárias insatisfatórias, e no estudo de Lima et al., (2005) com dietas enterais mostrou contaminação de $25 \%$ das amostras por coliformes totais, os quais podem ter tido origem por técnicas inadequadas de manipulação. A contaminação por coliformes totais observada no presente estudo, não garante, necessariamente, contaminação por coliformes termotolerantes, por isso, a etapa seguinte foi efetuada visando identificar o tipo de coliforme presente nas amostras.
Para serem considerados coliformes termotolerantes as bactérias devem possuir como hábitat exclusivo o trato intestinal do homem e de outros animais de sangue quente, estar presentes em grande quantidade nas fezes e ser resistentes ao ambiente extra-enteral (FRANCO; LANDGRAF, 2003, p. 27).

A Tabela 2 mostra os dados obtidos por meio de observações por 10 minutos dos manipuladores e o seu ambiente de trabalho, que por suas características é inadequado à finalidade proposta, produzir alimentos para consumo humano em larga escala de acordo com os dados expostos.

O ambiente em que os manipuladores trabalhavam, no momento da pesquisa, pode ser o veículo de contaminação dos coliformes totais, já que eles estão presentes no solo, além das fezes. Os insetos podem ser os veículos de transmissão de algumas das bactérias encontradas no presente estudo. Portanto, os dados apresentados informam as condições de higiene do ambiente, no qual se encontravam os manipuladores, ambiente esse inadequado à finalidade proposta.

Os estabelecimentos informais estão propícios à formação de focos de insalubridade (lixo ao redor do estabelecimento), podendo oferecer condições de risco pela presença de insetos e até de roedores.

As lixeiras dos estabelecimentos, em $100 \%$ dos casos, não apresentavam tampa, dos quais em $75 \%$ o acondicionamento era feito em sacos plásticos dispostos em baldes, em péssimas condições de higiene, favorecendo a proliferação dos insetos, fato observado no presente estudo, em que 
$100 \%$ das lixeiras apresentavam insetos que poderiam entrar em contato com o lanche, utensílios, manipuladores e ingredientes, aumentando o risco de contaminação. A presença de insetos durante a manipulação pode ser um fator de risco para contaminação dos lanches, assim como para os utensílios utilizados no porcionamento dos ingredientes, já que eles ficavam dispostos nos recipientes com os ingredientes ou em um único recipiente que armazenava vários talheres, os quais eram utilizados para porcionamento de todos os ingredientes. Segundo a CVS-6 de 1999, os talheres para porcionamento de ingredientes devem ser individuais, pois a utilização de talheres em conjunto pode acarretar contaminação de todos os ingredientes dos lanches (SÃO PAULO, 1999).

Os recipientes com os ingredientes observados na seguinte pesquisa ficavam abertos devido ao grande número de lanches produzidos durante 0 dia de trabalho para dar mais agilidade à produção, características desse tipo de lanche. Tal prática evidencia a importância de treinamento para manipuladores do serviço informal, visando aplicar práticas adequadas de higienização de alimentos.

A presença de insetos evidencia que os restos dos alimentos não são devidamente armazenados ou quando medidas para controle de pragas não são adotadas (CARDOSO; SOUZA; SANTOS, 2005). Medidas de controle para adequação da prática de higienização e conscientização da importância de manter os alimentos livres de focos de contaminação, como: lixo sem acondicionamento e armazenamento e armazenados incorretamente para coleta são necessárias. Segundo a CVS-6 de 1999 o lixo deve estar disposto adequadamente em lixeiras com tampas, constituída de material de fácil higiene de forma a não representar riscos de contaminação.

Tabela 2 - Distribuição das características observadas em estabelecimentos informais do município de Santo André

\begin{tabular}{|c|c|c|c|c|c|c|}
\hline \multirow[t]{2}{*}{ Elementos e características de observação } & \multicolumn{2}{|c|}{ Sim } & \multicolumn{2}{|c|}{ Não } & \multicolumn{2}{|c|}{$\begin{array}{l}\text { Não foi } \\
\text { possível } \\
\text { observar }\end{array}$} \\
\hline & $\mathbf{n}$ & $\%$ & $\mathbf{n}$ & $\%$ & $\mathbf{n}$ & $\%$ \\
\hline \multicolumn{7}{|l|}{ Lixo do estabelecimento } \\
\hline Recipiente com tampa e pedal & - & - & 12 & 100 & - & - \\
\hline Livre de roedores e insetos & - & - & 12 & 100 & - & - \\
\hline Armazenados para coleta & 9 & 75 & 3 & 25 & - & - \\
\hline \multicolumn{7}{|l|}{ Controle integrado de pragas } \\
\hline Presença de insetos no lixo do local & 12 & 100 & - & - & - & - \\
\hline Presença de insetos nas vias públicas & 7 & 58,33 & 5 & 41,67 & - & - \\
\hline $\begin{array}{l}\text { Presença de insetos nos ingredientes utilizados na } \\
\text { preparação dos lanches }\end{array}$ & 2 & 16,67 & 10 & 83,33 & - & - \\
\hline \multicolumn{7}{|l|}{ Utensílios de preparação } \\
\hline Local para guardar utensílios limpos & - & - & 12 & 100 & - & - \\
\hline Local de higienização dos utensílios & - & - & 12 & 100 & - & - \\
\hline \multicolumn{7}{|l|}{ Cuidados com utensílios e equipamentos } \\
\hline Lavar antes e após o uso & - & - & 12 & 100 & - & - \\
\hline Sempre pegar talheres pelo cabo & 12 & 100 & - & - & - & - \\
\hline Utensílios individuais & 4 & 33,33 & 8 & 66,67 & - & - \\
\hline \multicolumn{7}{|l|}{ Não é permitido } \\
\hline Varrer a seco & 2 & 16,67 & 6 & 50 & 4 & 33,33 \\
\hline Utilizar panos para secagem e limpeza de utensílios & 6 & 50 & 5 & 41,67 & 1 & 8,33 \\
\hline
\end{tabular}


$\mathrm{Na}$ Fig. 2 os tubos de ensaio inoculados mostrando a presença de gás no interior do tubo com consequente flutuação do Durhan e turvação do caldo devido à fermentação do carboidrato ali presente.

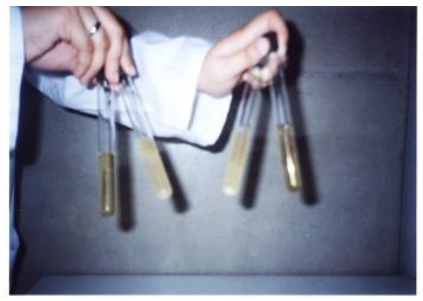

Fig. 2 - llustra os caldos EC com turvação após 24 horas em banho-maria.
Na Tabela 3 estão dispostos os dados decorrentes da etapa de confirmação da presença de coliformes termotolerantes nas amostras inoculadas em caldo EC. A formação de gás, assim como a flutuação do tubo de Durhan foram indicadores da presença desses tipos de bactérias indicando condições sanitárias insatisfatórias das mãos dos manipuladores de alimentos analisados.

\section{Tabela 3 - Distribuição de amostras inoculadas em caldo EC segundo formação de} gás e turvação.

\begin{tabular}{|c|c|c|c|c|c|c|}
\hline \multirow[b]{3}{*}{ Manipulador } & \multirow{2}{*}{\multicolumn{2}{|c|}{ Palma }} & \multicolumn{2}{|c|}{ Amostra } & \multirow{2}{*}{\multicolumn{2}{|c|}{ Dedo }} \\
\hline & & & & & & \\
\hline & Turvação & $\begin{array}{c}\text { Formação } \\
\text { de gás }\end{array}$ & Turvação & $\begin{array}{c}\text { Formação } \\
\text { de gás }\end{array}$ & Turvação & $\begin{array}{c}\text { Formação } \\
\text { de gás }\end{array}$ \\
\hline 1 & - & - & - & - & - & - \\
\hline 2 & + & + & + & + & - & + \\
\hline 3 & + & + & + & + & + & + \\
\hline 4 & + & + & + & + & + & + \\
\hline 5 & + & - & + & + & + & - \\
\hline 6 & + & + & + & - & + & + \\
\hline 7 & + & + & + & - & + & + \\
\hline 8 & - & - & + & - & + & - \\
\hline 9 & - & - & + & - & + & + \\
\hline 10 & + & + & + & - & + & + \\
\hline 11 & + & + & + & + & + & + \\
\hline 12 & + & + & + & + & + & - \\
\hline
\end{tabular}

Dentre as partes da mão analisadas, a unha com $91,66 \%$ das amostras apresentou turvação, seguido pelo dedo e a palma $(83,33 \%$ e $75 \%)$, respectivamente. Em compensação, a palma das mãos apresentou o maior índice de amostras que turvaram e obtiveram formação de gás (66.67\%) seguido pelo dedo (58,33\%) e a unha (50\%). Portanto, através dos dados acima apresentados, considerou-se a mão, como um todo. Ela é um dos principais veículos de contaminação por agentes infecciosos, pois toda superfície das mãos analisadas apresentou alto índice de contaminação por coliformes termotolerantes. A unha obteve o menor índice de formação de gás comparando com as outras partes das mãos analisadas com relação às amostras, mas por se tratar de um local de difícil acesso, onde tais microrganismos se alojam e se multiplicam, possivelmente o swab utilizado para coleta das amostras não coletou determinados microrganismos. Segundo a CVS-6 de 1999, 
as unhas, devem se apresentar curtas para evitar a proliferação e posterior contaminação dos alimentos e sem esmalte para evitar possíveis contaminações decorrentes de pedaços de esmaltes que podem eventualmente soltar-se da unha no momento do preparo dos lanches.

Falcão et al., (1983), realizando análise microbiológica de sorvetes artesanais, na cidade de Araraquara, SP, encontrou, em $75 \%$ das amostras, microorganismos pertencentes a esse grupo, indicando péssimas condições sanitárias de preparo desses produtos. Portanto, a manipulação artesanal de qualquer tipo de alimento corresponde a perigo potencial à saúde de quem os consome.

A Tabela 4 mostra os resultados obtidos na última etapa, na qual a Presença de E. coli foi evidenciada através da formação de colônias verde-brilhantes nas placas de EMB inoculado com a amostra que apresentou bactérias termotolerantes na etapa anterior.

Tabela 4 - Distribuição da contaminação de amostras com E. coli em placas de EMB inoculadas

\begin{tabular}{|c|c|c|c|c|c|c|}
\hline \multirow{3}{*}{ Manipulador } & \multicolumn{6}{|c|}{ Presença de E. coli } \\
\hline & \multicolumn{2}{|c|}{$\begin{array}{c}\text { Palma da mão e } \\
\text { punho }\end{array}$} & \multicolumn{2}{|c|}{ Unhas das mãos } & \multicolumn{2}{|c|}{ Dedos das mãos } \\
\hline & Sim & Não & Sim & Não & Sim & Não \\
\hline 1 & $\mathrm{x}$ & & & & & \\
\hline 2 & & $\mathrm{x}$ & & $x$ & & $\mathrm{X}$ \\
\hline 3 & & $\mathrm{X}$ & $x$ & & & $\mathrm{x}$ \\
\hline 4 & & $x$ & $x$ & & $x$ & \\
\hline 5 & & & $x$ & & & \\
\hline 6 & $x$ & & & & $x$ & \\
\hline 7 & $x$ & & & & $x$ & \\
\hline 8 & & & & & $\mathrm{X}$ & \\
\hline 9 & & & & & $\mathrm{X}$ & \\
\hline 10 & $x$ & & & & $x$ & \\
\hline 11 & $\mathrm{X}$ & & & $\mathrm{x}$ & $\mathrm{X}$ & \\
\hline 12 & & $\mathrm{x}$ & & $x$ & & \\
\hline Total & 5 & 4 & 3 & 3 & 7 & 2 \\
\hline
\end{tabular}

\section{Gráfico 1 - Distribuição das amostras inoculadas em caldo EMB}

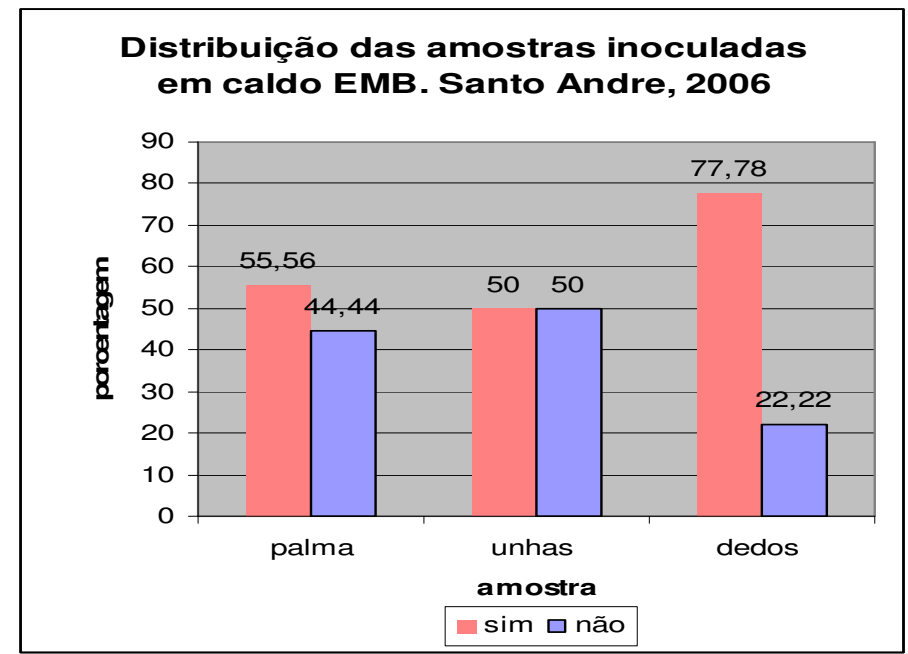


A Fig. 3 ilustra uma placa de meio EMB com colônias bacterianas de cloração verde-brilhante de bactérias $E$. coli.

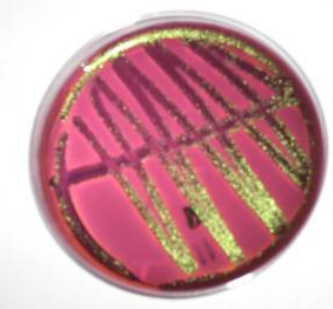

Fig. 3 - Placa de EMB com colônias da bactéria $E$. coli encontradas no presente estudo.

As bactérias enteropatogênicas como a $E$. coli, provenientes do intestino humano e de animais de sangue quente, quando encontradas em alimentos ou até mesmo nas mãos dos manipuladores como na presente pesquisa, indica qualidade higiênico-sanitária insatisfatória.

No presente estudo, das 24 amostras avaliadas e inoculadas em placas de EMB, 15 amostras $(62,5 \%)$ apresentaram colônias verde-brilhantes de $E$. coli. Dentre as 9 amostras analisadas das mãos e punho, 6 das unhas e 9 amostras dos dedos, obtevese o seguinte: $55,56 \%$, $50 \%$ e $77,78 \%$ de amostras contaminadas caracterizadas pela presença de colônias verde-brilhantes. O maior percentual de contaminação encontrado entre as amostras analisadas foi a dos dedos dos manipuladores.

O motivo de as amostras coletadas dos dedos dos manipuladores apresentarem maior contaminação, segundo os pesquisadores da análise microbiológica de mãos (FAGERNES; LINGAAS, 2001), é uso de anéis, proibido em utilização por manipuladores de alimentos de acordo com a CVS-6, pois podem veicular a contaminação por dificultar a higienização das mãos, que já é precária neste tipo de estabelecimento.

A contaminação por $E$. coli no presente estudo, apresentou percentuais elevados, quando comparados a estudos com dietas enterais, onde $10 \%$ das amostras apresentaram contaminação por este microorganismo (LIMA et al., 2005). Em hospitais, a fiscalização sanitária das preparações e manipuladores tem maior efetividade devido à necessidade de alimentos seguros a pessoas com capacidade imunológica deprimida. No entanto, a diferença nos percentuais dos estudos, evidencia 0 descaso com estabelecimentos informais quanto à fiscalização.

A contaminação por E. coli pode ocorrer de diversas formas. E, ao entrar no hospedeiro (homem), E. coli se fixa nas células, formando microcolônias que, por estarem unidas a elas, sua virulêncua aumenta, e com ela a probabilidade de se desenvolver a doença. O tipo de $E$. coli enterotoxigênica causa inibição da reabsorção de sódio. O intestino fica repleto de fluidos, resultando em diarreia líquida por dias. Outro tipo é a $E$. coli enteropatogênica, que ocorre principalmente em crianças e recém-nascidos que adquirem essa infecção durante o nascimento pelo útero. Essas atacam as células do intestino destruindo as microvilosidades. Devido ao público alvo dessa bactéria, e o grande consumo desse tipo de preparação por toda a população sem excluir faixas etária (crianças), ou estado físico (grávidas), medidas devem ser tomadas para evitar tal contaminação.

A Tabela 5 mostra os valores 
encontrados durante a observação de segundo estética adequada e a manipuladores de alimentos de uniformização.

estabelecimentos informais de Santo André

Tabela 5 - Distribuição das observações relacionadas com a estética adequada e uniformização de manipuladores

\begin{tabular}{lcccccc}
\hline & \multicolumn{2}{c}{ Sim } & \multicolumn{2}{c}{ Não } & $\begin{array}{c}\text { Não foi possível } \\
\text { observar } \\
\%\end{array}$ \\
Elementos e características de observação & $\mathbf{n}$ & $\%$ & $\mathbf{n}$ & $\%$ & $\mathbf{n}$ & $\begin{array}{c}\text { \% } \\
\text { Estética adequada }\end{array}$ \\
$\quad$ Barba feita diariamente e bigode aparado & 1 & 8,33 & - & - & 11 & 91,67 \\
$\quad$ Unhas curtas, limpas e livres de esmaltes & 3 & 25 & 9 & 75 & - & - \\
$\quad \begin{array}{l}\text { Adornos } \\
\text { Uniformização }\end{array}$ & 7 & 58,33 & 5 & 41,67 & - & - \\
$\quad$ Limpos & 5 & 41,67 & 4 & 33,33 & 3 & 25 \\
Bem conservados & 2 & 16,67 & 7 & 58,33 & 3 & 25 \\
$\quad$ Cor clara & 7 & 58,33 & 3 & 25 & 2 & 16,67 \\
$\quad$ Uso de tocas & - & - & 12 & 100 & - & - \\
$\quad$ Uso de luvas & - & - & 12 & 100 & - & - \\
\hline
\end{tabular}

A utilização de adornos por manipuladores de alimentos, além de unhas longas e/ou com esmalte são fatores de risco para contaminação dos alimentos. Os adornos dificultam a higienização das mãos, pois o desinfetante não consegue atingir toda a superfície das mãos, ou em alguns casos são inativados na presença de sujidades que possam estar presentes nas mãos dos manipuladores decorrentes da presença desses adornos (SILVA JR., 2008). Com isso, as bactérias contidas na região da mão que não sofreu ação do desinfetante poderão contaminar os alimentos que 0 manipulador tiver contato. Portanto, 58,33\% dos manipuladores apresentaram fator de risco alto para contaminação dos alimentos pela utilização de adornos, como anéis durante a preparação dos lanches.

As unhas compridas comportam grande número de microorganismos, dentre eles patógenos, como $E$. coli em casos de higiene-sanitária inadequada. Durante 0 contato da região da mão contaminada com
- alimento, tais bactérias se alojam e começam a se multiplicar de forma que, quando este é consumido, essas bactérias patogênicas colonizam o intestino delgado causando sintomas como náuseas, vômitos, etc. (FORSYTHE, 2002).

A ação corretiva nesses casos seria retirar todo e qualquer adorno, além de manter as unhas curtas, limpas e higienizadas, assim como toda a mão e antebraço antes de manipular alimentos de acordo com a CVS-6 de 1999.

É importante a utilização de uniformes em bom estado de conservação e higiene por funcionários dos serviços de alimentação, pois uniformes em condições higiênicas inadequadas podem tornar-se transmissores em potencial de contaminações.

No estudo de Cardoso, Souza e Santos (2005), realizado em UAN formal, os resultados apresentaram significativa diferença quanto à uniformização dos 
funcionários: $55 \%$ faziam uso de uniformes e $90 \%$ de aventais. No presente estudo, a uniformização adequada dos manipuladores foi praticamente nula.

Dos aventais por eles utilizados, $33,33 \%$ apresentavam sujidades evidentes, $58,33 \%$ se encontravam em mal estado de conservação e $25 \%$ eram de cores escuras, tais como: azul-marinho ou verde-escuro.

Sabe-se que as condições microbiológicas dos alimentos podem estar relacionadas com as práticas dos manipuladores, como os uniformes e aventais por eles utilizados. Comparando os dois estudos, pode-se concluir que, os manipuladores de estabelecimentos informais apresentam higiene pessoal insatisfatória, fato que pode levar a contaminação dos alimentos por eles produzidos e seu consumo poderá acarretar surtos alimentares.

Manipuladores de serviços de alimentação devem fazer uso de uniformes completos, de cor clara, bem conservados e limpos, com troca diária (CVS-6, 1999). O uso de uniformes completos, ou seja, calça, avental de manga longa e sapato evitam possíveis acidentes relacionados a queimaduras além de proteger o alimento de contaminação, já que a cor clara dos uniformes facilita a identificação de sujidades e consequentemente necessidade de troca deles.

Observa-se o desconhecimento por parte dos manipuladores da importância de aventais em perfeitas condições e livres de sujidades para evitar qualquer tipo de contaminação que possa ser veiculado por ele.

A Tabela 6 apresenta outros dados obtidos durante a observação dos manipuladores na cidade de Santo André. As condições higiênico-sanitárias das mãos dos manipuladores dos estabelecimentos informais analisados estão dispostas a seguir:

Tabela 6 - Distribuição das observações relacionadas com a necessidade de higienização das mãos e o local de higienização correta

\begin{tabular}{|c|c|c|c|c|c|c|}
\hline \multirow[t]{2}{*}{ Elementos e características de observação } & \multicolumn{2}{|c|}{ Sim } & \multicolumn{2}{|c|}{ Não } & \multicolumn{2}{|c|}{$\begin{array}{c}\text { Não foi possível } \\
\text { observar }\end{array}$} \\
\hline & $\mathbf{n}$ & $\%$ & $\mathbf{n}$ & $\%$ & $\mathbf{n}$ & $\%$ \\
\hline \multicolumn{7}{|l|}{ Higiene das mãos } \\
\hline Troca de função & - & - & 12 & 100 & - & - \\
\hline Após limpar, utilizar panos e material de limpeza & - & - & 11 & 91,67 & 1 & 8,33 \\
\hline Após contato com o lixo & - & - & - & - & 12 & 100 \\
\hline Tocar em alimentos crus ou não higienizados & - & - & 9 & 75 & 3 & 25 \\
\hline Manusear dinheiro & - & - & 12 & 100 & - & - \\
\hline Fumar & - & - & - & - & 12 & 100 \\
\hline Entre manipulação de alimentos crus e cozidos & - & - & 7 & 58,33 & 5 & 41,67 \\
\hline Tossir & - & - & - & - & 12 & 100 \\
\hline Entrar em contato com o uniforme & - & - & 12 & 100 & - & - \\
\hline \multicolumn{7}{|l|}{ Local para higienizacão das mãos } \\
\hline Lixeira acionada por pedal & - & - & 11 & 91,67 & 1 & 8,33 \\
\hline Papel tolha & - & - & 11 & 91,67 & 1 & 8,33 \\
\hline Torneira acionada sem conato manual & - & - & 11 & 91,67 & 1 & 8,33 \\
\hline Lavatório exclusivo para higienização das mãos & - & - & 11 & 91,67 & 1 & 8,33 \\
\hline Sabão líquido & - & - & 11 & 91,67 & 1 & 8,33 \\
\hline Água corrente & - & - & - & - & 12 & 100 \\
\hline
\end{tabular}


A higiene adequada das mãos pode eliminar ou diminuir o risco de contaminação dos alimentos por $E$. coli e todas as outras bactérias. De acordo com os dados apresentados na Tabela 3 pode-se inferir que a higienização das mãos não foi adequada.

Em relação à higiene das mãos, no questionário aplicado ao manipulador, todos afirmaram lavar as mãos com água e sabão várias vezes durante o dia de trabalho, 0 que não foi averiguado durante 0 questionário observativo. Já no momento da coleta das amostras para análise laboratorial era nítida a baixa qualidade higiênicosanitária da superfície das mãos dos manipuladores. Comparando a afirmação com o questionário observativo, obtiveram-se os seguintes resultado: durante 10 minutos de observação nenhum dos 12 manipuladores lavou as mãos, mesmo após manipular dinheiro, entrar em contato com superfícies não higienizadas, celular, entre outros. Outra fonte de contaminação encontrada nos estabelecimentos informais foi 0 uso de panos por $50 \%$ dos manipuladores. $E$ como os panos eram utilizados para limpeza de equipamentos, entravam em contato com restos de alimentos e líquidos, permanecendo sobre o carrinho, próximo aos compartimentos aquecidos por muito tempo para contínuo uso do manipulador. Tais atitudes favorecem a multiplicação microbiana por fornecer todas as características necessárias para proliferação dos mesmos. Após contato com o pano, os manipuladores não tinham qualquer cuidado com a higienização das mãos, sendo, portanto uma ótima fonte de contaminação.
Em estudo de Akutsu et al. (2005), em $83,34 \%$ dos restaurantes comerciais analisados, apresentaram condições desfavoráveis de manipulação. As UAN em $40 \%$ não atingiram as especificações de higienização adequada das mãos. Entre os locais analisados por Akutsu et al., (2005) os hotéis apresentaram melhor adequação às normas com apenas $10 \%$ dos estabelecimentos com condições desfavoráveis.

A qualidade higiênico-sanitária de estabelecimentos formais não é 100\% adequada, mas, quando comparados a estabelecimentos informais como os da presente pesquisa, observou-se a melhor prática de higienização das mãos, propiciando um melhor produto final com relação à qualidade microbiológica. A maior fiscalização de unidades formais por órgãos capacitados como a Vigilância Sanitária pode ser o motivo pelo qual o índice de higienização de mãos seja maior ou mais frequente.

A limpeza das mãos durante a manipulação dos alimentos ocorria somente quando elas se apresentavam muito sujas, utilizando-se galões de água e detergente doméstico em $75 \%$ dos casos, e em $25 \%$ em lanchonetes situadas nas proximidades do estabelecimento. Em 91,67\% dos locais onde ocorria higienização ou lavagem das mãos, não apresentavam lixeira acionada por pedal, evidenciando-se o possível contato das mãos com a lixeira. Papel toalha não era utilizado e, em seu lugar, o pano constituía a forma de secagem das mãos lavadas na rua. Não se sabe dizer se o pano para secagem das mãos era o mesmo utilizado para limpeza dos equipamentos 
dos estabelecimentos. De acordo com a CVS-6 de 1999, após lavar as mãos, secar com papel toalha não reciclado descartável, ar quente ou qualquer outro procedimento adequado. Aconselha-se a estabelecimentos informais o uso de papel toalha pelo menor custo sendo, portanto, mais acessível ao manipulador.

A higienização das mãos pela deficiência de estrutura adequada em estabelecimentos informais fixos ou próximos a eles, não ocorre adequadamente. Dessa forma, o risco de contaminação não diminui após a lavagem das mãos. Sugere-se que os órgãos responsáveis tomem atitudes para minimizar os riscos de contaminação dos alimentos comercializados em vias públicas, pois seu consumo é muito alto e frequente. Treinamento e melhor estrutura deveriam ser oferecidos aos manipuladores, cadastrando-os de forma a poder acompanhar a qualidade higiênico-sanitária dos lanches mais facilmente, já que esse tipo de estabelecimento se instala em diversos lugares, principalmente para driblar a fiscalização ou procurar melhores pontos de venda, visando maior lucro.

Segundo Silva Jr. (2008), o manipulador deve lavar as mãos com frequência com água, sabão e um antiséptico, por, no mínimo, 10 vezes durante o dia de trabalho, fato não presenciado durante a observação dos manipuladores a distância pelos pesquisadores. De acordo com Almeida et al., (1995), mesmo a mais rigorosa lavagem das mãos não é garantida a eliminação completa dos microrganismos. Entretanto, a lavagem rigorosa com sabão, anti-séptico e água morna é o primeiro requisito de higiene pessoal aconselhado ao manipulador antes, durante e após a manipulação de alimentos ou usarem instalações sanitárias.

No entanto, no mesmo estudo observou-se que concentrações mais elevadas de iodóforos $(5 \mathrm{~mL})$ destrói as formas inativas dos microrganismos patogênicos, mas como existe risco de ingestão de resíduos tóxicos provenientes da higienização das mãos, formulações à base de iodóforos, não são aconselhadas por se tratar de manipulação de alimentos (SILVA JR., 2008), já que em pessoas normais, o consumo menor ou igual a 1 $\mathrm{mg} /$ dia não produz efeitos imediatos, mas em pessoas hipertireódicas podem causar inibição na produção de tiroxina. Seu consumo durante semanas pode levar a um quadro de hipertireoidismo em pessoas normais (SILVA JR., 2008).

Os dados acima mencionados, para higienização das mãos, anti-sépticos, como álcool $70 \%$ a 1,30 - 1,40 minutos (mãos secas), ou 2,50 - 3,00 minutos (mãos úmidas), devem ser utilizados, já que a utilização de álcool $70 \%$ líquido ou na forma de gel apresentou resultados microbiológicos semelhantes ao obtido com a utilização de álcool iodado, ou seja, não se faz necessária a utilização de iodo na antisepsia das mãos (SILVA JR., 2008, p. 273).

Aconselha-se a utilização de galões de água anexados aos carrinhos. A abertura deve ficar voltada para baixo, sendo regulado o fluxo de água através de uma torneira. A água utilizada deve ser armazenada em um recipiente localizado abaixo do galão de água, sendo descartada em local apropriado após término do trabalho. 
O uso de luvas no preparo final dos alimentos é necessário para evitar contaminação decorrente da manipulação. No entanto, todos os manipuladores que participaram da pesquisa, não faziam uso de luvas na preparação dos lanches.

De acordo com a legislação do município de São Paulo, Lei n: 12039 de 11/04/1996 - DOM SP de 12/04/ 1996 e o decreto n: 36152 de 13/06/1996 - DOM SP 14/04/1996, ela "obriga o uso de luvas plásticas descartáveis pelos funcionários dos estabelecimentos do setor de alimentação diretamente envolvidos no manuseio e preparo de refeição". Esse procedimento deve ser acompanhado pela técnica de lavagem das mãos, pois qualquer possível contato da mão nua com o alimento poderá causar contaminação, já que a formação de suor nas mãos provoca a multiplicação dos microrganismos patogênicos (SILVA JR., 2008).

O estudo de Bryan, citado por Silva Jr. (2008), demonstrou $30 \%$ de contaminação das mãos sem proteção e $31 \%$ em mãos com luvas de plástico. Não houve diferença significativamente entre as mãos sem proteção ou com luvas descartáveis, mostrando que as luvas não diminuem o número a carga microbiana.

Considerando a virulência dessa bactéria termotolerante no organismo humano quando são deslocados do seu sítio normal no corpo (intestino), para um sítio anormal (bocal), via fecal-oral, evidencia a necessidade em ações corretivas visando diminuir a evidência de amostras contaminadas para melhorar a qualidade sanitária dos alimentos produzidos. Visando evitar que os microrganismos contaminem, sobrevivam, recontaminem e se multipliquem nos alimentos, deve-se desenvolver um "manual de boas práticas", (critérios de segurança no controle higiênicosanitário integrado com os princípios do sistema APPCC são indispensáveis). Ele define os pontos críticos (PC) nos quais os perigos podem estar presentes nos alimentos e informar os procedimentos de controle para evitar a ocorrência de perigos.

O treinamento e capacitação devem envolver atividades para instruir os profissionais que trabalham no preparo de alimentos quanto às técnicas operacionais e de controle higiênico-sanitário. Durante o treinamento os temas higiene pessoal; lavagem e anti-sepsia das mãos e informações importantes sobre a higiene corporal, uniforme e cuidados gerais; higiene ambiental: utilização de desinfetantes mais indicados para higienização de equipamentos; higiene dos alimentos, utilização de desinfetantes próprios para alimentos e informação sobre tempo e temperaturas limites para evitar multiplicação microbiana, devem ser abordados (SILVA JR., 2008).

A necessidade de treinamento a esses manipuladores é evidente. Devido ao fato de que fazer cursos preparatórios não é uma prática comum entre os manipuladores de alimentos de estabelecimentos fixos informais. De acordo com os dados obtidos $83,33 \%$ dos manipuladores nunca fizeram qualquer tipo de curso de higiene alimentar. Os demais $16,67 \%$ afirmaram ter feito, mas há muito tempo atrás. Os motivos pelos quais não fizeram qualquer tipo de curso sobre higienização alimentar alegados pelos manipuladores foram: 8 afirmaram não 
haver interesse de sua parte, falta de oportunidade, falta de tempo, não gostar da área em que trabalha, não precisou para ser admitido como manipulador. É importante enfatizar que para exercer tal profissão não há qualquer exigência sobre capacitação através de cursos ou treinamentos, por se tratar de estabelecimentos informais.

A Tabela 7 mostra o número de manipuladores dono ou não do comércio em que trabalhava no momento da pesquisa relacionado com ter ou não feito algum tipo de curso preparatório de higiene alimentar.

\section{Tabela 7 - Disposição do número de manipuladores segundo cursos e tipo de comércio.

\begin{tabular}{lccc}
\hline Cursos & Próprio & $\begin{array}{c}\text { Comércio } \\
\text { Não-próprio }\end{array}$ & Total \\
\hline Sim & 2 & 0 & 2 \\
Não & 1 & 9 & 10 \\
Total & 3 & 9 & 12 \\
\hline \multicolumn{4}{c}{$\mathrm{P}<1 \%$}
\end{tabular}

A partir dos resultados da Tabela 7, pode-se afirmar que, quando o manipulador é o proprietário, há maior interesse em realizar treinamentos. De acordo com os dados acima, observa-se que para ser qualificado a produzir esse tipo de alimento (lanche), não é necessário qualquer tipo de capacitação. Esse conceito deveria ser revisto pelos órgãos competentes para evitar as Doenças Transmitidas por Alimentos (DTA's) muito frequentes neste século.

Observou-se que $75 \%$ dos manipuladores eram contratados, ao quais apresentavam as seguintes características: todas do sexo feminino, com idade entre 15 e 25 anos (66,67\%) e com mais de 25 anos $(33,33 \%)$, entre as quais $77 \%$ cursaram ensino médio, sendo $42,86 \%$ completado e $57,14 \%$ incompletos com os estudos, e $22,22 \%$ apresentaram grau de escolaridade fundamental completo.

Os dados dessa pesquisa demonstraram grande número de amostras contaminadas por E. coli no presente estudo. Essa é uma bactéria termotolerante encontrada apenas no intestino humano e de animais de sangue quente, mostrando que seu contágio tem origem sanitária. Tal resultado chama a atenção para necessidade de práticas corretivas de higiene, visando diminuir o risco de surtos alimentares veiculados por alimentos produzidos em vias públicas. Observou-se também que o local onde os alimentos são preparados é inadequado, pois apresenta vários pontos de risco para contaminação das preparações além do próprio manipulador. A necessidade de instalações adequadas para produção de um alimento sanitariamente seguro se torna evidente nas situações encontradas no presente estudo. A fiscalização desse tipo de estabelecimento se faz necessária, já que o consumo desse tipo de lanche é cada vez maior entre a população brasileira.

\section{CONCLUSÃO}

O presente estudo verificou a presença de colônias do coliforme 
termotolerante E. coli em $62,5 \%$ das amostras analisadas.

São vários os fatores que podem ser destacados para a contaminação das mãos desses manipuladores como: os uniformes em péssimas condições de higiene, a presença de insetos, práticas inadequadas de manipulação, assim como a não higienização das mãos podem ser os veículos de contaminação por coliformes totais, termotolerantes entre eles a E. coli. O alto índice de contaminação por $E$. coli observadas caracteriza a deficiência estrutural quanto ao ambiente de trabalho e a desqualificação dos manipuladores.

\section{REFERÊNCIAS}

AKUTSU, R. de C. et al. Adequação das boas práticas de fabricação em serviços de alimentação. Campinas: revista de nutrição, v. 18, n. 3, p. 419-427, maio/jun., 2005.

ALMEIDA, R. C. de C. et al. Avaliação e controle da qualidade microbiológica de mãos de manipuladores de alimentos. Revista de saúde pública, v. 29, n. 4, p. 290294, 1995.

CARDOSO, R. de C. V.; SOUZA, E. V. A. de; SANTOS, P. Q. dos. Unidades de alimentação e nutrição nos campi da universidade federal da Bahia: um estudo sobre a perspectiva do alimento seguro. Campinas: Revista de nutrição, v. 18, n. 5, p. 669-680, set./out., 2005.

FAGERNES, M.; LINGAAS, E. Factors interfering with the microflora on hands: a regression analysis of samples from 465 healthcare workers. J Adv Nurs, v. 67, n. 2, p. 297-307, FEB., 2011.
FALCÃO, D. P. et al. Exame microbiológico de sorvetes não pasteurizados. São Paulo: revista de saúde pública, v. 17, p. 2-8, 1983.

FORSYTHE, S. J. Microbiologia da segurança alimentar. In:

Introdução de alimentos seguros. Porto Alegre, RS: artmed, p. 14-15, 2002.

FRANCO, B. D. G.; LANDGRAF, M. Microbiologia de alimentos. 2 ed. São Paulo: Editora Atheneu, 2003.

LIMA, A. R. da C. et al. Avaliação microbiológica de dietas enterais manipuladas em um hospital. Natal: Acta cirúrgica brasileira, v. 20, n. 1, p. 27-30, 2005.

LUCCA, A.; TORRES, E. A. Condições de higiene de cachorro-quente comercializado em vias públicas. São Paulo: revista de saúde pública, v. 36, n. 3, junho, 2002.

São Paulo. Secretaria da Saúde do Estado de Pão Paulo. Portaria CVS-6 de 10 de março de 1999. Regulamento técnico que estabelece os parâmetros e critérios para o controle higiênico-sanitário em estabelecimentos de alimentos. São Paulo, 1999.

SILVA JUNIOR, E. A. Manual de controle higiênico-sanitário em serviços de alimentação. 6. ed. atual. São Paulo, SP: Varela, 2008.

SOUSA, C. L; CAMPOS, G. D. Condições higiênico-sanitárias de uma dieta hospitalar. Campinas: revista de nutrição, v. 16, n. 1, p. 127-134, jan/mar., 2003.

TRABULSI, L. R.; ALTERTHUM, F. Microbiologia. In: TRABULSI, L. R.; ORDOÑES, J. G.; MARTINEZ, M. B. Enterobacteriacease, cap. 35, 4 ed. São Paulo: atheneu, p. 269-276, 2005. 


\section{ANEXO I - Questionário com informações pessoais}

\section{Nome do manipulador}

2. Idade do manipulador

( ) de 15 a 25 ( ) de 25 a 35 ( ) 35 a 55 ( ) mais de 55

3. Sexo
( ) Feminino
( ) Masculino

4. Escolaridade

( ) Fundamental ( )Médio ( ) Superior ( ) analfabeto - ( ) completo ( ) incompleto

5. Fez algum curso de higienização alimentar?

( ) $\operatorname{sim}($ ) não

6. Se sim, qual o motivo? Se não por quê?

7. Quanto tempo trabalha neste local?

( ) de dias a 1 mês ( ) 1,1 mês a 5 meses ( ) 5.1 mês a 10 meses ( ) mais de 10 meses

8. Quantos dias da semana você trabalha neste local?

( ) de 1 a 3 dias ( ) de 4 a 6 ( ) todos os dias

9. Quantos alimentos são produzidos diariamente?

( ) de 20 a 50 lanches ( ) mais de 50 lanches

10. Costuma lavar as mãos durante a manipulação de lanches e o pagamento dos mesmos?

( ) $\operatorname{sim}($ ) não

11. Se não, por quê?

( ) falta de tempo ( )não há local ( )pela distância entre o lavatório e o estabelecimento （ ） outros, qual

12. Quantas vezes durante o dia você costuma lavar as mãos?

( ) de 1 a 3 vezes ( ) de 4 a 6 ( ) mais de 6

13. O comércio é próprio?

( ) $\operatorname{sim}($ ) não

14. Utiliza luvas descartáveis na preparação dos lanches?

( ) $\operatorname{sim}($ ) não

15. Se sim, quantas luvas você costuma utilizar durante o dia de trabalho?

( ) de 1 a 3 ( ) de 4 a 6 ( ) mais de 6

16. Onde são armazenados os componentes dos lanches que não estão sendo utilizados?

( ) isopores ( ) embalagens convencionais fechadas ( ) embalagens convencionais abertas ( ) outros, qual:

17. Qual o procedimento de lavagem das mãos, inclusive produtos utilizados? 
ANEXO II - Questionário Observativo

\begin{tabular}{|l|c|c|c|c|}
\hline Instalações sanitárias & Sim & Não & $\begin{array}{l}\text { Não se aplica/ Não foi } \\
\text { possível observar }\end{array}$ & observações \\
\hline Separado por sexos & $($ ) & $($ ) & $($ ) & \\
\hline $\begin{array}{l}\text { Com vasos sanitários e } \\
\text { mictórios e lavatórios }\end{array}$ & $($ ) & $($ ) & $($ ) & \\
\hline Serviço de água corrente & $($ ) & $($ ) & $($ ) & \\
\hline $\begin{array}{l}\text { Pisos e azulejos em bom } \\
\text { estado }\end{array}$ & $($ ) & $($ ) & $($ ) & \\
\hline lluminação e ventilação & $($ ) & $($ ) & \\
\hline
\end{tabular}

Observações:

\begin{tabular}{|l|c|c|c|c|}
\hline Lixo do estabelecimento & Sim & Não & $\begin{array}{c}\text { Não se aplica/ Não foi } \\
\text { possível observar }\end{array}$ & observações \\
\hline $\begin{array}{l}\text { Recipiente com tampa e } \\
\text { pedal }\end{array}$ & $($ ) & $($ ) & $($ ) & \\
\hline Livre de roedores e insetos & $($ ) & $($ ) & $($ ) & \\
\hline Armazenados para coleta & $($ ) & $($ ) & $($ ) & \\
\hline
\end{tabular}

Observações:

\begin{tabular}{|l|c|c|c|c|}
\hline Utensílios de preparação & Sim & Não & $\begin{array}{c}\text { Não se aplica/ Não foi } \\
\text { possível observar }\end{array}$ & observações \\
\hline $\begin{array}{l}\text { Local para guardar e } \\
\text { utensílios limpos }\end{array}$ & $($ ) & $($ ) & $($ ) & \\
\hline $\begin{array}{l}\text { Local de higienização dos } \\
\text { utensílios }\end{array}$ & $($ ) & $($ ) & $($ ) & \\
\hline
\end{tabular}

Observações:

\begin{tabular}{|l|c|c|c|c|}
\hline $\begin{array}{l}\text { Cuidados com utensílios e } \\
\text { equipamentos }\end{array}$ & Sim & Não & $\begin{array}{l}\text { Não se aplica/ Não foi } \\
\text { possível observar }\end{array}$ & observações \\
\hline Lavar antes e após o uso & $($ ) & $($ ) & $($ ) & \\
\hline $\begin{array}{l}\text { Sempre pegar talheres pelo } \\
\text { cabo }\end{array}$ & $($ ) & $($ ) & $($ ) & \\
\hline Utensílios individuais & $($ ) & $($ ) & $($ ) & \\
\hline
\end{tabular}

Observações:

\begin{tabular}{|c|c|c|c|c|}
\hline Higienização das mãos & Sim & Não & $\begin{array}{l}\text { Não se aplica/ Não foi } \\
\text { possível observar }\end{array}$ & observações \\
\hline Lixeira acionada por pedal & () & $($ ) & $($ ) & \\
\hline Papel toalha & $(1)$ & $(1)$ & $(1)$ & \\
\hline $\begin{array}{l}\text { Torneira acionada sem } \\
\text { contato manual }\end{array}$ & $\begin{array}{ll}1 & 1 \\
(1)\end{array}$ & $(1)$ & $(\quad)$ & \\
\hline $\begin{array}{l}\text { Lavatórios exclusivos para } \\
\text { higienização das mãos }\end{array}$ & $(\quad)$ & () & $($ ) & \\
\hline Sabão líquido & () & $($ ) & () & \\
\hline Água corrente & $(1)$ & $(1)$ & () & \\
\hline
\end{tabular}

Observações: 


\begin{tabular}{|l|c|c|c|c|}
\hline Não é permitido & Sim & Não & $\begin{array}{c}\text { Não se aplica/ Não foi } \\
\text { possível observar }\end{array}$ & observações \\
\hline Varrer a seco & $($ ) & $($ ) & $($ ) & \\
\hline $\begin{array}{l}\text { Usar panos para secagem } \\
\text { para secagem dos utensílios } \\
\text { e equipamentos }\end{array}$ & $($ ) & $($ ) & $($ ) & \\
\hline
\end{tabular}

Observações:

\begin{tabular}{|l|c|c|c|c|}
\hline Estética adequada & Sim & Não & $\begin{array}{c}\text { Não se aplica/ Não foi } \\
\text { possível observar }\end{array}$ & observações \\
\hline $\begin{array}{l}\text { Barba feita diariamente e } \\
\text { bigode aparado }\end{array}$ & $($ ) & $($ ) & $($ ) & \\
\hline $\begin{array}{l}\text { Unhas curtas, limpas e livres } \\
\text { de esmalte }\end{array}$ & $($ ) & $($ ) & $($ ) & \\
\hline adornos & $($ ) & $($ ) & $($ ) & \\
\hline
\end{tabular}

Observações:

\begin{tabular}{|l|c|c|c|c|}
\hline Uniformização & Sim & Não & $\begin{array}{c}\text { Não se aplica/ Não foi } \\
\text { possível observar }\end{array}$ & observações \\
\hline Limpos & $($ ) & $($ ) & $($ ) & \\
\hline Bem conservados & $($ ) & $($ ) & $($ ) & \\
\hline Cor clara & $($ ) & $($ ) & $($ ) & \\
\hline Uso de tocas & $($ ) & $($ ) & $($ ) & \\
\hline Uso de luvas & $($ ) & $($ ) & $($ ) & \\
\hline
\end{tabular}

Observações:

\begin{tabular}{|l|c|c|c|c|}
\hline $\begin{array}{l}\text { Controle integrado de } \\
\text { pragas }\end{array}$ & Sim & Não & $\begin{array}{l}\text { Não se aplica/ Não foi } \\
\text { possível observar }\end{array}$ & observações \\
\hline $\begin{array}{l}\text { Presença de insetos no lixo } \\
\text { do local }\end{array}$ & $($ ) & $($ ) & $($ ) & \\
\hline Nas vias públicas & $($ ) & $($ ) & $($ ) & \\
\hline $\begin{array}{l}\text { Ingredientes utilizados na } \\
\text { preparação dos lanches }\end{array}$ & $($ ) & $($ ) & $($ ) & \\
\hline
\end{tabular}

Observações:

\begin{tabular}{|c|c|c|c|c|}
\hline Higiene das mãos & Sim & Não & $\begin{array}{l}\text { Não se aplica/ Não foi } \\
\text { possível observar }\end{array}$ & observações \\
\hline Troca de função & () & $($ ) & () & \\
\hline $\begin{array}{l}\text { Após limpar, utilizar panos e } \\
\text { material de limpeza }\end{array}$ & ( ) & ( ) & ( ) & \\
\hline Após contato com o lixo & () & $(\mathbf{)}$ & () & \\
\hline $\begin{array}{l}\text { Tocar em alimentos crus ou } \\
\text { não higienizados }\end{array}$ & ( ) & ( ) & ( ) & \\
\hline Manusear dinheiro & () & $(\mathbf{)}$ & $(\mathbf{)}$ & \\
\hline fumar & () & () & () & \\
\hline $\begin{array}{lll}\text { Entre } \quad \text { manipulação } & \text { de } \\
\text { alimentos crus e cozidos } & \\
\end{array}$ & $(1)$ & $(1)$ & ( ) & \\
\hline tossir & () & $($ ) & () & \\
\hline $\begin{array}{l}\text { Entrar em contato com o } \\
\text { uniforme, bancada etc. }\end{array}$ & $(1)$ & ( ) & ( ) & \\
\hline
\end{tabular}

Observações: 